Dragana Drobnjak*

UDK 811.133.1'373.7

Snežana Gudurić

$811.134 .2 ’ 373.7$

Ksenija Šulović

$811.163 .41^{\prime} 373.7$

Filozofski fakultet

DOI: $10.19090 / \mathrm{gff} .2018 .2 .165-180$

Univerzitet u Novom Sadu

Originalni naučni rad

\title{
FRAZEMI SA SOMATIZMOM GLAVA U FRANCUSKOM, ŠPANSKOM I SRPSKOM JEZIKU Konceptualno polje 'čovekovo ponašanje' ${ }^{* *}$
}

U radu razmatramo francuske, španske i srpske frazeme sa somatizmom fr. tête / šp. cabeza / srp. glava koji pripadaju semantičkom polju 'čovekovo ponašanje', s ciljem da utvrdimo (ne)istovetnost koncepata koje oni izražavaju, kao i (ne)podudarnost njihove leksičkosemantičke strukture. Korpus, ekscerpiran iz opštih i frazeoloških rečnika i elektronskih izvora, pripada standardnom francuskom, španskom i srpskom jeziku. Raznolikost korpusa zahtevala je dva pristupa u klasifikaciji građe, te smo u prvu grupu uvrstile frazeme utemeljene na pojmovnim metaforama, a u drugu one analizirane metodom semantičke dekompozicije.

Ključne reči: lingvokulturologija, frazem, glava, konceptualno polje 'čovekovo ponašanje', francuski, španski, srpski.

\section{UVOD}

Somatizmi, kao frazeološke i jezičke univerzalije, odlikuju se izuzetnim tvorbenim, semantičkim i frazeološkim potencijalom (Matijašević, 2003), kao i visokom frekventnošću (Kovačević, 2012). Somatski frazemi ${ }^{1}$ izrazito su antropocentrični i antropometrični, i izviru iz univerzalno prisutnih pojmovnih metafora motivisanih čovekovim telesnim iskustvom. Mnogi od njih upućuju na čovekovo ponašanje i na njegov odnos prema sredini u kojoj se nalazi.

\footnotetext{
*dragana.drobnjak@ff.uns.ac.rs

** Rad je napisan u okviru projekta Jezici i kulture u vremenu i prostoru (broj 178002), koji finansira Ministarstvo prosvete, nauke i tehnološkog razvoja Republike Srbije.

${ }^{1}$ Pod frazemom podrazumevamo osnovnu jedinicu frazeologije, koja se sastoji iz najmanje dveju komponenata, i koju karakterišu čvrsta struktura, ustaljenost, reproduktivnost i idiomatičnost (Burger, 2003).
} 
Stoga u ovom radu $^{2}$ želimo da ispitamo na koji se način čovekovo ponašanje odslikava $\mathrm{u}$ somatskim frazemima sa komponentom glava $^{3} \mathrm{u}$ francuskom, španskom i srpskom jeziku, s ciljem da utvrdimo (ne)istovetnost koncepata koje oni izražavaju. Pod ponašanjem podrazumevamo odgovor na kakav stimulus iz spoljašnje sredine ili posledicu kakvog unutrašnjeg procesa. Ono češće podrazumeva pokret, a ređe njegovo odsustvo. Svako ponašanje može se neposredno opaziti i izmeriti (Levitis, Lidicker \& Freund, 2009: 105). Čovekovo ponašanje ${ }^{4}$ može biti svesno ili nesvesno, voljno ili nevoljno, prikriveno ili otvoreno, shodno stepenu njegove prilagođenosti prirodnoj i društvenoj sredini, odnosno proceni situacije u kojoj se nalazi. Posebno je značajna priroda čovekovog ponašanja prema osobama sa kojima je u neposrednom kontaktu, pri čemu je takav vid ponašanja podložan uticajima trenutnih okolnosti i društvenog okruženja (Cao, 2010).

Leksičko-semantička raznolikost frazema zahtevala je dva pristupa u klasifikaciji građe, te smo u prvu grupu uvrstile frazeme utemeljene na pojmovnim metaforama, a u drugu one analizirane metodom semantičke dekompozicije.

Pod leksičkim poklapanjem podrazumevamo prisustvo istih ili sličnih komponenata u frazemima triju jezika, a pod semantičkim - istovetan koncept koji oni izražavaju. Frazeme istog ili sličnog značenja ali neistovetne leksičke strukture smatramo delimičnim ekvivalentima, te ih stoga posebno navodimo. Kod francuskih i španskih primera čiji ekvivalent u srpskom jeziku ne pronalazimo $u$ zagradi najpre dajemo doslovan prevod komponenata frazema (često agramatičan i obeležen znakom *), a potom i frazeološko značenje (među navodnicima). Doslovno značenje frazeoloških komponenata veoma je važan kriterijum, budući da odnos doslovnog i frazeološkog značenja ukazuje na (ne)prozirnost motivacije i određuje stepen idiomatičnosti (Drobnjak-Šulović, 2016).

Korpus za ovo istraživanje čini 108 frazema (38 francuskih, 37 španskih i 33 srpska) koji su ekscerpirani iz francuskih, španskih i srpskih opštih i frazeoloških rečnika i iz elektronskih izvora. Svi frazemi u korpusu potvrđeni su u savremenoj

${ }^{2}$ Prvi deo našeg istraživanja frazema sa somatizmom glava objavljen je u Godišnjaku Filozofskog fakulteta u Novom Sadu broj XLIII/1 (2018), pod naslovom „Frazemi sa somatizmom glava u francuskom, španskom i srpskom jeziku. Konceptualno polje 'čovekove osobine"'.

${ }^{3}$ O somatizmu glava videti i: Cortès, 1998-1999; Razdobudko-Čović, 2003; Dragićević, 2009; Andrić, 2013; Ristić, 2013; Trivić, 2015; Štrbac-Štasni, 2017.

${ }^{4}$ Više o ponašanju videti u: Lorenz, 1987. 
jezičkoj praksi i pripadaju standardnim varijantama francuskog, španskog i srpskog jezika.

Frazemske varijante koje ne ugrožavaju stabilnost frazeološke strukture, njeno monolitno značenje i reproduktivnost (npr. šp. sacar, quitar alguien algo de la cabeza a alguien; srp. popeti se, penjati se kome na glavu; biti, visiti, stajati kome nad glavom) u našoj analizi posmatrane su kao istovetne.

\section{POJMOVNE METAFORE U FRAZEMIMA SA SOMATIZMOM GLAVA}

Pojmovna metafora predstavlja kognitivni mehanizam kod kojeg se jedan iskustveni domen (izvorni) delimično projektuje na drugi iskustveni domen (ciljni), tako da se ovaj drugi delimično poima pomoću prvog. Izvorni domen je konkretan (mada ne uvek) i jasno definisan pojam (npr. ljudsko telo, životinje, zdravlje, bolest, mašine, građevine, igre, sport, hrana, svetlost, toplota), za razliku od ciljnog domena, koji je najčešće apstraktan (npr. emocije, moralne kategorije, želje, mišljenje, društvo, politika, religija, ekonomija, međuljudski odnosi, vreme) (Kövecses, 2002) ${ }^{5}$. U našem istraživanju i izvorni i ciljni domen su konkretni.

$\mathrm{U}$ analizi metafora ne polazimo od značenja celokupnog iskaza, nego od semantike glagola koji su u najbližem okruženju posmatranog somatizma, i od kojih zapravo zavisi njegova konceptualizacija. Tako, na primer, $\mathrm{u}$ frazemu isterati kome bubice, mušice iz glave ne uzimamo u obzir značenje ,urazumiti, dozvati pameti”, nego posmatramo glagol isterati i njegove dopune (npr. iz kuće, iz učionice, iz zemlje, otuda i iz glave).

U skladu sa ovakvom metodologijom, frazeme smo razvrstale u tri grupe, prema pojmovnim metaforama na kojima su utemeljeni.

2.1. GLAVA JE PROSTOR. U kognitivnoj lingvistici GLAVA se prvenstveno konceptualizuje kao ČOVEKOV MENTALNI PROSTOR ${ }^{6}$, koji se razume pomoću metafore MENTALNI PROSTOR JE FIZIČKI PROSTOR, odnosno MENTALNI PROSTOR JE SADRŽATELJ ispunjen raznolikim mentalnim entitetima (npr. mislima, idejama,

\footnotetext{
${ }^{5}$ O pojmovnim metaforama videti više u: Barcelona, 2003; Johnson, 1987; Klikovac, 2000; Kövecses, 2000; 2002; 2005; Lakoff, 1987; 1993; Lakoff-Johnson, 1980; 1999; Soriano, 2012; Wierzbicka, 1999.

6 Pored „mentalnog prostora”, čoveka odlikuje i “emocionalni prostor” koji se razume pomoću metafore EMOCIONALNI PROSTOR JE FIZIČKI PROSTOR / SADRŽATELJ. U njemu su smeštena osećanja i/ili predmeti od posebne emocionalne vrednosti za čoveka (DrobnjakŠulović, 2016: 16).
} 
slikama, predstavama) koji se konceptualizuju kao SADRŽINA KOJA ISPUNJAVA ČOVEKOV MENTALNI PROSTOR.

$\mathrm{Na}$ ovim metaforama temelje se frazemi kojima se iskazuje nametanje kakve misli, želje, sumnje, ili kakvog prohteva:

fr. remplir la tête à quelqu'un / šp. llenar la cabeza a alguien / srp.

(na)puniti glavu kome;

fr. enfoncer, faire entrer quelque chose dans la tête de quelqu'un / šp. - / srp. utuviti kome šta u glavu;

fr. - / šp. ponérsele, metérsele en la cabeza (*staviti mu ga/je u glavu) / srp. -;

fr. - / šp. - / srp. uliti kome šta u glavu;

fr. - / šp. - / srp. uterati kome pamet u glavu.

Istovetnu semantiku imaju i naredni frazemi, zasnovani na podmetafori SADRŽINA KOJA SE UBACUJE U GLAVU JE FIZIČKA POJAVA. Ova ontološka podmetafora preliva se potom u pojmovni lanac, budući da generiše dalje konkretizacije: SADRŽINA KOJA SE UBACUJE U GLAVU JE BIĆE $\rightarrow$ SADRŽINA KOJA SE UBACUJE U GLAVU JE INSEKT $\rightarrow$ SADRŽINA KOJA SE UBACUJE U GLAVU JE BUBA $\mathrm{i}$ SADRŽINA KOJA SE UBACUJE U GLAVU JE CRV. Celokupan pojmovni lanac utemeljen je na sekundarnim značenjima leksema 'buba' i 'crv' koja su iznedrila metafore NEUGODNA MISAO JE CRV i NEOSNOVANA/NASTRANA MISAO JE BUBA:

fr. - / šp. - / srp. ubaciti, staviti kome bubu u glavu;

fr. - / šp. - / srp. ubaciti, staviti kome crva u glavu.

Ove podmetafore uočavamo i u francuskim frazemima chercher des poux dans la tête de quelqu'un (*tražiti vaške u nečijoj glavi, ,uznemiravati, dosađivati”) i (ne pas) savoir ce que quelqu'un a dans la tête (*(ne) znati šta neko ima u glavi, „(ne) znati šta neko misli”), kao i u španskom frazemu llenar, henchir a alguien la cabeza de viento (*napuniti, naduvati glavu vetrom, „laskati kome”).

Nepoželjni entiteti mogu da se uklone iz GLAVE kao MENTALNOG PROSTORA / SADRŽATELJA:

fr. faire effacer quelqu'un, quelque chose de la tête de quelqu'un / šp. borrar pensamiento de la cabeza / srp. izbrisati kome koga, šta iz glave;

fr. - / šp. levantar de su cabeza (*podići iz svoje glave, „pretvarati se, izmišljati”) / srp. -;

fr. - / šp. traer, llevar de cabeza (*doneti, nositi iz glave, ,izazvati, stvarati kome nevolje") / srp. - .

GLAVA se dalje konkretizuje kao PROSTORIJA SA PROZORIMA/VRATIMA iz koje takođe mogu da se udalje ovakvi entiteti: 
fr. faire sortir, faire chasser quelque chose, quelqu'un de la tête de quelqu'un / šp. sacar, quitar alguien algo de la cabeza a alguien / srp. izbaciti, isterati kome koga, šta iz glave;

fr. - / šp. abrir la cabeza (*otvoriti glavu, „,snažno udariti, pretući”) / srp. - ;

fr. - / šp. - / srp. isterati kome bubice, mušice iz glave.

2.1.1. GLAVA JE LOKALIZATOR. Prostorne odnose čine objekat lokalizacije, lokalizator kao pozadinski elemenat u prostornim odnosima i orijentir (jezički elemenat, najčešće predlog) kojim se određuje njihov odnos (Piper, 1997: 21-22).

U narednim frazemima somatizam GLAVA poima se kao LOKALIZATOR, a u svega nekoliko frazema iskazan je i objekat lokalizacije (šećer, mladunčad, prnje).

Francuski frazem casser du sucre sur la tête de quelqu'un (*razbiti šećera na nečijoj glavi) ima negativnu konotaciju i upućuje na kritikovanje osobe koja nije prisutna.

Negativno su obojeni i španski frazemi izrazito netransparentne pozadinske slike - echar de cabeza (*baciti s glave, „izdati koga”), hundir de cabeza (*potopiti s glave, ,izdati koga"), darle duro y a la cabeza (*dati mu tvrdo i u glavu, ,podsticati nekoga da napadne neku osobu”, tirar los cachorros a la cabeza (*baciti mladunčad u glavu, „naglo raskinuti neki odnos”), tirarse los trastos a la cabeza (*baciti prnje na glavu, ,izneti prljav veš prilikom prepirke između dveju osoba").

Dok je nemarkiranost obeležje španskog frazema encasquetar en la cabeza (*navući na glavu, ,ubediti koga”), frazem traer, poner sobre cabeza (*doneti, staviti na glavu) ima osobito pozitivnu konotaciju i u njemu se glava konceptualizuje kao mesto na kojem se nalazi poštovanje.

Pojedini srpski frazemi ističu nelogično i neuobičajeno ponašanje koje se poredi sa obrnutim, neprirodnim položajem tela u prostoru - dubiti na glavi, postaviti se na glavu, prevrnuti šta na glavu, postaviti, postavljati šta na glavu.

Uporno nadgledanje druge osobe ili dosađivanje izražava se srpskim frazemom popeti se, penjati se kome na glavu. Istu semantiku ima i frazem biti, visiti, stajati kome nad glavom.

Izrazito negativnu konotaciju nalazimo u srpskom frazemu $u$ glavu koga biti, ubiti, tucati, utući, gde se jedan akter sa nipodaštavanjem odnosi prema drugom akteru, dovodeći ga do kakvog negativnog psihičkog stanja.

Glava se u srpskom jeziku konceptualizuje i kao lokalizator nagomilavanja obaveza, briga, problema, koji se poimaju kao konkretni predmeti - natovariti sebi šta na glavu. Španski frazem llevar en la cabeza (*nositi na glavi, „imati 
probleme") slikovito prikazuje glavu kao mesto na kojem se nalaze neprijatnosti i neuspesi.

2.2. ORIJENTACIONE METAFORE. Frazemi utemeljeni na orijentacionim pojmovnim metaforama nastaju na iskustvenoj osnovi odmeravanjem prostornih

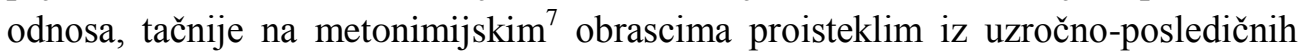
odnosa između kakvog stanja ili radnje i propratnih telesnih pokreta. Reč je, zapravo, o tipičnom bihejvioralnom efektu prijatnih ili neprijatnih emocija, pri čemu telesne reakcije omogućavaju metonimiju ,efekat/posledica za uzrok” (npr. podignuta/spuštena glava).

Izvorne domene orijentacionih metafora čine pojmovi kao što su: gore/dole, unutra/spolja, blizu/daleko, napred/nazad, duboko/plitko, centralno/periferno (otuda, na primer, metafore: BOLJE JE NAPRED, BUDUĆNOST JE ISPRED ČOVEKA, KONTROLA I MOĆ SU GORE, TUGA JE DOLE, LOŠIJI JE IZA, AKTIVNO JE GORE, PASIVNO JE DOLE).

U narednim frazemima uočavamo orijentacionu metaforu POZITIVNO EMOTIVNO STANJE JE GORE, odnosno njenu podmetaforu PONOSITO PONAŠANJE JE GORE. One su utemeljene na svakodnevnom čovekovom iskustvu da prijatno emotivno stanje i propratno ponašanje podrazumevaju uzdignutu glavu:

fr. aller, porter haut la tête, la tête haute / šp. ir con la cabeza (bien) alta / srp. ići visoko podignute glave.

Nasuprot tome, u pojedinim frazemima prisutna je orijentaciona pojmovna metafora NEGATIVNO JE DOLE koja je generisala podmetafore POKORNOST JE DOLE $i$ SRAM JE DOLE. One su utemeljene na čovekovom iskustvu da neprijatna stanja podrazumevaju pognutu glavu:

fr. baisser, courber la tête / šp. agachar, bajar la cabeza / srp. saviti, sagnuti, pognuti glavu.

Frazeme sa komponentom glava koji upućuju na kakvo naglo i nepromišljeno delanje pronalazimo prevashodno $u$ francuskom jeziku i u njima se

\footnotetext{
${ }^{7}$ A. Barselona (Barcelona, 2003) smatra da su sve metafore zasnovane na metonimiji, a postojanjem konceptualnog preduslova za metaforu objašnjava njihovu motivisanost. Za razliku od metafore, koja se zasniva na preslikavanju pojmovne strukture iz jednog domena $\mathrm{u}$ drugi, pojmovna metonimija predstavlja preslikavanje pojmovne strukture u okviru istog domena, odnosno jedan pojmovni domen konceptualizuje se pomoću nekog svog dela.
} 
uočava orijentaciona metafora NAGLO I NEPROMIŠLJENO DELANJE JE NAPRED, odnosno NAGLO I NEPROMIŠLJENO DELANJE JE DOLE:

fr. se jeter, se lancer la tête la première (*baciti se, vinuti se glave prve, „nepromišljeno se upustiti u nešto”) / šp. - / srp. -;

fr. foncer tête première (*jurnuti glave prve, ,nepromišljeno se upustiti u nešto") / šp. - / srp. -;

fr. se jeter, se lancer la tête baissée (*baciti se, vinuti se glave spuštene, „nepromišljeno nešto uraditi”) / šp. - / srp. -;

fr. foncer tête baissée (*jurnuti glave spuštene, ,nepromišljeno nešto uraditi”) / šp. - / srp. - .

Svesno zatvaranje očiju pred neprijatnostima, odnosno bežanje od stvarnosti izražava se frazemima zasnovanim na orijentacionoj metafori NESUOČAVANJE SA NEPRIJATNOSTIMA JE DOLE I UNUTRA:

fr. se cacher, se mettre la tête dans le sable / šp. esconder, meter la cabeza en la arena / srp. gurati, gurnuti, zavući, sakriti, sakrivati glavu u pesak.

Nasuprot tome, savladavanje teškoća, odnosno izlazak iz kakve teške situacije izražava se frazemima zasnovanim na sledećim orijentacionim metaforama:

- PREVAZILAŽENJE TEŠKOĆA JE POKRET KA SPOLJA:

fr. sortir la tête de l'eau (*izvaditi glavu iz vode) / šp. - / srp. -;

- PREVAZILAŽENJE TEŠKOĆA JE POKRET NAGORE:

fr. relever, redresser la tête / šp. levantar la cabeza / srp. podići glavu.

Frazemi kojima se ističe prezauzetost utemeljeni su na orijentacionoj metafori PREZAUZETOST JE DOLE:

fr. - / šp. no levantar, no alzar cabeza / srp. ne dizati, ne dići glavu.

2.3. GLAVA JE MATERIJA. Prototipična materija prostire se potencijalno beskonačno, nema granice, a time ni oblik (npr. tečnost). Po izgledu i osobinama ona je ista $u$ svim delovima (Klikovac, 2000), može da teče i da se sipa, vidljiva je, opipljiva i pruža otpor kretanju. Prototipičnu materiju opažamo putem više čula.

Ulančavanje marginalnijih članova kategorije MATERIJE može da ide u pravcu 'otvrdnjavanja'. Manje čvrsti članovi (npr. prašina, pesak) ne mogu da teku, ali mogu da se sipaju, za razliku od onih potpuno čvrstih (npr. drvo, mermer, kamen), koji nemaju tu mogućnost.

Pored 'otvrdnjavanja', marginalniji članovi kategorije MATERIJE mogu biti podložni 'razređivanju', te se ne opažaju svim čulima (npr. dim, para, svetlost).

U korpusu smo uočile nekoliko konkretizacija metafore GLAVA JE MATERIJA: 
- GLAVA JE MATERIJA KOJA MOŽE DA SE ZAGREJE:

fr. - / šp. calentarle la cabeza a alguien (*zagrejati glavu kome, „obmanjivati koga”) / srp. -;

- GLAVA JE MATERIJA KOJA MOŽE DA SE JEDE:

fr. - / šp. comerle la cabeza a alguien (*jesti glavu kome, „dodijavati, dosađivati kome") / srp. -;

- GLAVA JE ČVRSTA MATERIJA:

fr. fendre, casser la tête à quelqu'un (*prepoloviti, slomiti glavu kome, ,zamarati koga, dosađivati kome”) / šp. quebrarle, quebrantar a alguien la cabeza (*slomiti glavu kome, ,zamarati koga, dosađivati kome") / srp. -;

fr. - / šp. - / srp. probi(ja)ti kome glavu.

U francuskom frazemu se payer la tête de quelqu'un (*platiti sebi glavu nečiju, „rugati se”) prisutna je podmetafora GLAVA JE ROBA. Pod robom se podrazumevaju kako materije tako i predmeti, te se u ovom frazemu somatizam glava istovremeno može konceptualizovati i kao MATERIJA i kao PREDMET. Prototipični predmet je trodimenzionalan, opipljiv (čvrst), perceptivno odvojiv od okoline (ima oblik na osnovu kojeg se može prepoznati) i funkcionalan (prenosiv je i može se njime rukovati). On može da se javi u različitim oblicima, ali mora da ostane prepoznatljiv. U našem istraživanju glavu posmatramo kao prototipičan predmet samo u slučajevima u kojima se ona poima kao odvojiva od tela.

\section{SEMANTIČKA DEKOMPOZICIJA FRAZEMA SA SOMATIZMOM GLAVA}

Frazeme u ovom odeljku analizirale smo prema semantičkom kriterijumu, sledeći metodu semantičke dekompozicije Dobrovoljskog (prema: Zybatow, 1997: 582) koji predlaže 'tehniku grozdova', prema kojoj frazeme istog grozda povezuje semantička sličnost na intuitivnom nivou. Frazemima se pridružuju odgovarajući deskriptori, zapravo njihova relevantna obeležja zasnovana na sličnosti. Kontekst je često presudan za pridruživanje deskriptora frazemima, te pojedine višeznačenjske frazeme može da karakteriše više deskriptora. S druge strane, frazemi unutar jednog grozda, združeni u značenjsku celinu zahvaljujući istom relevantnom obeležju, ne moraju obavezno da dele isti deskriptor.

3.1. U ovoj skupini sabrani su frazemi kojima se izražavaju najraznolikiji vidovi čovekovog ponašanja.

U samo jednom slučaju ustanovile smo leksičko-semantičko podudaranje, i to između francuskog frazema tourner la tête à quelqu'un i srpskog zavrteti 
kome glavu, u kojima subjekat svojim ponašanjem nastoji da opčini, zavede ili zadivi drugog aktera.

Suprotstavljanje sagovorniku i zalaganje za sopstvene stavove izražava francuski frazem tenir tête à quelqu'un (*držati glavu kome). Sličnu semantiku, sa nijansom prkosa ili hirovitosti, ima i španski frazem obscurecerse (a alguien) la cabeza (*smračiti se (kome) glava).

Dva francuska frazema upućuju na ponašanje prouzrokovano kakvim osećanjima, prevashodno besom, nezadovoljstvom, razočaranjem, iznenađenošću:

- 'duriti se':

fr. faire la tête (*činiti glavu) /

šp. - / srp. -;

- 'licem izraziti kakvo osećanje':

fr. faire une drôle de tête (*činiti smešnu glavu) /

šp. - / srp. - .

Pojedini deskriptori svojstveni su samo francuskim ili španskim, prevashodno negativno obojenim frazemima:

- '(za)komplikovati sebi život, otežati sebi život':

fr. se prendre la tête (*sebi uzeti glavu) / šp. - / srp. -;

- 'dosađivati kome', 'zadavati brige kome':

fr. prendre la tête à quelqu'un (*uzeti glavu kome) / šp. - / srp. -;

- 'ukoriti koga', 'oštro, strogo (kome) prigovoriti':

fr. laver la tête de quelqu'un (*prati glavu nečiju) / šp. - / srp. -;

fr. savonner la tête de quelqu'un (*sapunati glavu nečiju) / šp. - / srp. -;

- 'sprečiti koga da iznese svoje mišljenje':

fr. trancher la tête à quelqu'un (*odseći glavu kome) / šp. - / srp. -;

- 'svađati se, tući se':

fr. faire une tête au carré à quelqu'un (*činiti glavu na četvrtasto kome) / šp. - / srp. -;

fr. mettre la tête au carré à quelqu'un (*staviti glavu na četvrtasto kome) / šp. - / srp. -;

- 'uništiti, prekinuti nešto':

fr. - / šp. no dejar títere con cabeza (*ne ostaviti marionetu sa glavom) / srp. -;

- 'nametnuti se radi postizanja boljeg društvenog položaja':

fr. - / šp. meter la cabeza en alguna parte (*staviti glavu na neku stranu) / srp. -;

- 'preklinjati koga':

fr. - / šp. quebrarse la cabeza (*slomiti sebi glavu) / srp. -. 
Pozitivno su konotirana samo dva španska frazema:

- 'pokazati se, odvažiti se pred drugima':

fr. - / šp. sacar la cabeza (*izvući glavu) / srp. -;

- 'posvetiti pažnju kome':

fr. - / šp. volvérsele la cabeza a alguien (*vratiti mu se glava kome) / srp.--

3.2. Frazemi u ovoj skupini izražavaju svojevrstan okolnosni okvir kakvog čovekovog ponašanja. Najbrojniji su oni kojima se specifikuje način odvijanja kakve radnje. Tako u trima lingvokulturološkim zajednicama hladna glava ukazuje na smireno i razumno ponašanje:

fr. faire quelque chose la tête froide / šp. hacerlo con la cabeza fría / srp. raditi šta hladne glave.

Čovekovo tvrdoglavo, uporno, ali često uzaludno delanje, uglavnom u beznadežnim i bezizlaznim situacijama, iskazuje se kroz kontakt glave sa kakvom (obično čvrstom) materijom:

fr. se taper, se cogner la tête contre les murs / šp. darse con la cabeza en la pared / srp. lupati, udarati (lupiti, udariti, tresnuti) glavom o, u zid; fr. - / šp. meter la cabeza en el puchero (*staviti glavu u paprikaš) / srp. -; fr. - / šp. - / srp. ići, hteti glavom kroz zid.

Naredni frazemi upućuju na kakvo naglo i nepromišljeno postupanje:

fr. faire quelque chose sur un coup de tête (*činiti šta na udarac glave) / šp. - / srp. - ;

fr. prendre, faire quelque chose bile en tête (*uzeti, činiti šta žuči u glavi) / šp. - / srp. -;

fr. - / šp. liarse la manta a la cabeza (*omotati glavu ćebetom) / srp. -;

fr. - / šp. correr como pollo sin cabeza (*trčati kao kokoška bez glave) / srp. - .

Srpski frazemi kao muva bez glave (ići, trčati, juriti) i kao bez glave (juriti, bežati, trčati, ići) ističu besmislenu užurbanost, odnosno besciljno i smeteno kretanje, a frazem glavom bez obzira (pobeći, uteći) i brzinu udaljavanja izazvanu strahom.

I ovde uočavamo da su pojedini frazemi kojima se kvalifikuje čovekovo ponašanje svojstveni samo jednom od posmatranih jezika:

- 'u četiri oka, bez svedoka':

fr. tête à tête (*glava u glavu) / šp. - / srp. -;

- 'neprincipijelno nešto raditi':

fr. à la tête du client (*po glavi mušterije) / šp. - / srp. -; 
- 'delati shodno sopstvenoj odluci, bez ičijeg uticaja':

fr. n'en faire qu'à sa tête (*činiti ga samo po svojoj glavi) / šp. - / srp. -;

fr. - / šp. hacerlo por su cabeza (*činiti to po svojoj glavi) / srp. -;

- 'raditi nešto svim srcem, posvetiti se nečemu u potpunosti':

fr. - / šp. meter la cabeza en algo (*staviti glavu u nešto) / srp. -;

- 'neprijatno iznenaditi koga':

fr. - / šp. - / srp. udariti koga kao maljem po glavi, posred glave.

Svega nekoliko frazema izražava merne odnose. Tako je istovetna konstrukcija spacijalnog tipa u francuskom i srpskom jeziku - fr. par-dessus la tête / srp. preko glave - motivisana primarnim semantičkim sadržajem lekseme glava ('deo tela koji se nalazi na njegovom vrhu'), iz kojeg proističe kvantifikativno, odnosno intenzifikativno značenje ,veoma mnogo, previše”, kojim se označava najviši stepen realizacije kakve radnje (npr. fr. avoir du travail par-dessus la tête / srp. imati posla preko glave; srp. zadužiti se preko glave; srp. preko glave preturiti, premetnuti, prevaliti). Ukoliko pak nije u pitanju subjektova, već glava drugog aktera, srpska spacijalna struktura preko čije glave (raditi, činiti nešto) ukazuje na kakvu tajnu radnju koja se odvija bez znanja tog drugog aktera.

U srpskom frazemu kao oko, oči u glavi kvantifikuje se kakvo čovekovo ponašanje (npr. čuvati, paziti) i u njemu je uočljivo prisustvo dvaju somatizama primarne komponente oko i sekundarne glava. Ovaj frazem motivisan je semom vrednosti proisteklom iz značaja očiju za čoveka i utemeljen je na ontološkoj pojmovnoj metafori OČI SU DRAGOCEN PREDMET, koja se ukršta sa metaforom GLAVA JE SADRŽATELJ.

Francuskim frazemom gagner d'une courte tête (*pobediti za kratku glavu) izražava se minimalna prednost ostvarena u završnici nekog takmičenja.

\section{ZAKLJUČAK}

U radu smo uporedile francuske, španske i srpske frazeme sa somatizmom fr. tête / šp. cabeza / srp. glava koji se odnose na semantičko polje ’čovekovo ponašanje'. Ustanovile smo da su oni u posmatranim jezicima znatno manje zastupljeni (108) u odnosu na frazeme koji izražavaju čovekove fizičke, karakterne, umne i moralne osobine (174). ${ }^{8}$

\footnotetext{
${ }^{8}$ Videti u: Šulović, Drobnjak \& Gudurić, 2018: 337-356.
} 
Analiza korpusa pokazala je da posmatrani somatizam ima sličan frazeološki potencijal u trima lingvokulturološkim zajednicama (38 francuskih, 37 španskih i 33 srpska frazema). Uprkos brojčanoj ujednačenosti frazema u našoj građi, veoma je uočljiva njihova strukturna i semantička raznolikost, budući da smo u korpusu uočile veliki broj bezekvivalentnih frazema ( 25 francuskih, 26 španskih i 20 srpskih), prema svega 9 slučajeva poklapanja u trima jezicima (ukupno 27 frazema), odnosno 5 slučajeva poklapanja u dvama jezicima (francuski/španski - 1, španski/srpski - 1 , francuski/srpski - 3). Ovakva raznolikost nametnula je dva pristupa u klasifikaciji građe: $\mathrm{s}$ jedne strane utemeljenost na pojmovnim metaforama, a sa druge metodu semantičke dekompozicije.

Frazemi utemeljeni na pojmovnim metaforama (65) brojniji su od frazema razvrstanih prema semantičkom kriterijumu (43).

Među pojmovnim metaforama najzastupljenija je GLAVA JE MENTALNI PROSTOR / SADRŽATELJ u kojem se nalaze RAZNOLIKI ENTITETI (npr. misli, ideje, sumnje, bube) konceptualizovani kao SADRŽINA KOJA ISPUNJAVA GLAVU. Pojedine bezekvivalentne primere u ovoj skupini možemo da objasnimo činjenicom da se nekoliko frazema istovetne semantike različito leksički formalizuje u trima jezicima.

Izvorni domeni nešto manje brojnih orijentacionih metafora su GORE, DOLE, NAPRED, UNUTRA i SPOLJA. Ova skupina najupečatljivija je po broju, inače retkih, leksičko-semantičkih poklapanja u trima jezicima (4), za razliku od skupine isključivo bezekvivalentnih, prevashodno španskih i srpskih, frazema u kojima se GLAVA konceptualizuje kao LOKALIZATOR, odnosno kao pozadinski elemenat u prostornim odnosima.

Brojčano najoskudnija jeste skupina frazema utemeljenih na metafori GLAVA JE MATERIJA.

Kriterijum semantičke dekompozicije pokazao se najprimerenijim za klasifikovanje (prevashodno bezekvivalentnih) frazema kojima se izražavaju, s jedne strane, raznoliki vidovi čovekovog ponašanja, i, sa druge, kvalifikovanje ili kvantifikovanje kakvog čovekovog delanja.

Većina frazema negativno je konotirana i upućuje na nepoželjno čovekovo ponašanje (npr. tuča, raskid, ogovaranje, izdaja, svađa, obmanjivanje, durenje, nagomilavanje obaveza). Pozitivno konotirani frazemi prisutni su u neznatnom broju slučajeva (npr. prevazilaženje teškoća, izražavanje poštovanja, ponosito ponašanje). 
Dragana Drobnjak, Snežana Gudurić, Ksenija Šulović

PHRASEMES WITH THE LEXEME HEAD IN FRENCH, SPANISH AND SERBIAN

Semantic field 'human behavior'

Summary

This paper deals with a comparison of French, Spanish and Serbian phrasemes containing the lexeme Fr. tête / Sp. cabeza / Ser. glava that qualify human behavior. In spite of their almost equal number in our corpus (38 French, 37 Spanish and 33 Serbian phrasemes), their structural and semantic diversity is conspicuous, which led to two different approaches to classification and, consequently, resulted in two groups of phrasemes. The first group consists of items based on conceptual metaphors and the second of those analyzed by semantic decomposition.

Phrasemes based on conceptual metaphors (65) are more numerous than those classified according to the semantic criterion (43).

Most of the phrasemes have a negative connotation and indicate either undesirable human behavior or a situation generating such behavior (e.g. fights, break-ups, gossip, betrayal, quarrels, deception, sulkiness, being overburdened with obligations and duties, etc.). Phrasemes with a positive connotation occur in a very small number of cases (e.g. overcoming difficulties, expressing respect, taking pride in something, etc.).

Key words: linguoculturology, phraseme, head, semantic field 'human behavior', French, Spanish, Serbian

\section{LITERATURA}

Andrić, E. (2013). Kontrastivna semantička analiza reči fej u mađarskom i glava u srpskom jeziku. Zbornik Matice srpske za filologiju i lingvistiku, knj. 56, sv. 2: $131-153$.

Barcelona, A. (ed.) (2003). Metaphor and Metonymy at the Crossroads. Berlin / New York: Mouton de Gruyter.

Burger, H. (2003). Phraseologie. Eine Einführung am Beispiel des Deutschen. Berlin: Erich Schmidt Verlag.

Cortès, C. (1998-1999). Phraséologie et corps humain. Etude comparative de la représentation du corps humain dans les expressions phraséologiques en français et en allemand. Cahier du C.I.E.L., 6: 85-109.

Cao, L. (2010). In-depth Behavior Understanding and Use: the Behavior Informatics Approach. Information Science, 180 (17): 3067-3085.

Dragićević, R. (2009). O problemima identifikacije frazeologizama. Südslavistik online, 1: 35-44. 
Drobnjak, D., Šulović, K. (2016). Lingvokulturološki triptih. Novi Sad: Filozofski fakultet.

Klikovac, D. (2000). Semantika predloga. Beograd: Filološki fakultet.

Kovačević, B. (2012). Hrvatski frazemi od glave do pete. Zagreb: Institut za hrvatski jezik i jezikoslovlje.

Kövecses, Z. (2000). Metaphor and Emotion: Language, Culture, and Body in Human Feeling. Cambridge: Cambridge University Press.

Kövecses, Z. (2002). Metaphor. A Practical Introduction. New York: Oxford University Press.

Kövecses, Z. (2005). Metaphor in Culture: Universality and Variation. Cambridge: Cambridge University Press.

Lakoff, G. (1987). Women, Fire, and Dangerous Things, What Categories Reveal about the Mind. Chicago: University of Chicago Press.

Lakoff, G. (1993). The contemporary theory of metaphor. Metaphor and Though. Cambridge: Cambridge University Press, 202-252.

Lakoff, G., Johnson, M. (1980). Metaphors We Live by. Chicago: University of Chicago Press.

Lakoff, G., Johnson, M. (1999). Philosophy in the flesh: the embodied mind and its challenge to Western thought. New York: Basic Books.

Levitis, D., Lidicker, W. Z., Jr. \& Freund, G. (2009). Behavioural biologists do not agree on what constitutes behaviour. Animal Behaviour, 78: 103-110.

Lorenz, K. (1987). Temelji etologije. Zagreb: Globus.

Piper, P. (1997). Jezik i prostor. Beograd: Biblioteka XX vek.

Razdobudko-Čović, L. (2003). Semantika i pragmatika somatizama u srpskom $i$ ruskom jeziku. Beograd: Vedes. (štampano ćirilicom)

Ristić, G. (2013). Somatizmi u nemačkoj i srpskoj frazeologiji (kontrastivna istraživanja). Univerzitet u Novom Sadu, Filozofski fakultet. (doktorska disertacija)

Soriano, C. (2012). La metáfora conceptual. Lingüística Cognitiva. Barcelona: Anthropos, 97-121.

Trivić, A. (2015). Leksičko-semantička analiza somatizama u frazeologiji savremenog španskog $i$ srpskog jezika: kontrastivni pristup. Univerzitet u Kragujevcu, FILUM. (doktorska disertacija)

Štrbac, G., Štasni, G. (2017). Somatizmi i konceptualizacija stvarnosti u srpskom jeziku. Novi Sad: Filozofski fakultet. (štampano ćirilicom)

Šulović, K., Drobnjak, D. \& Gudurić, S. (2018). Frazemi sa somatizmom glava u francuskom, španskom i srpskom jeziku. Konceptualno polje 'čovekove 
osobine'. Godišnjak Filozofskog fakulteta u Novom Sadu, XLIII/1, 337356.

Wierzbicka, A. (1999). Emotions across Languages and Cultures, Diversity and Universals. Cambridge: Cambridge University Press.

Zybatow, L. (1997). Idiome und Parömien aus kognitivlinguistischer und translationslinguistischer Sicht (am Beispiel des Russischen und Ukrainischen). U: Spillmann, O., Warnke, I. (Hrsg.) (1997). Internationale Tendenzen der Syntaktik, Semantik und Pragmatik. Akten des 32. Linguistischen Kolloquiums in Kassel 1997, Peter Lang - Europäischer Verlag der Wissenschaften. 579-588.

\section{IZVORI}

Ashraf, M., Miannay, D. (1995). Dictionnaire des expressions idiomatiques françaises. Paris: Librairie générale de France.

Buitrago, A. (2000). Diccionario de dichos y frases hechas. Madrid: Editorial Espasa Calpe, S. A.

Clave Diccionario de uso del español actual. (2002). Madrid: Ediciones SM.

DRAE: Diccionario de la lengua española. (1992). Madrid: Real Academia Española.

Drašković, V. (1990). Francusko-srpskohrvatski frazeološki rečnik. Beograd: Zavod za udžbenike i nastavna sredstva.

Johnson, M. (1987). The Body in the Mind: The Bodily Basis of Meaning, Imagination, and Reason. Chicago: University of Chicago Press.

Larousse, Dictionnaire encyclopédique illustré. (1993). Paris: Larousse.

Le nouveau Petit Robert, Dictionnaire alphabétique et analogique de la langue française. (2005). Paris: Robert.

Matijašević, J. (2003). Semantičko-derivacioni rečnik. Sv. 1: Čovek - delovi tela (red. D. Gortan-Premk, V. Vasić, Lj. Nedeljkov). Novi Sad: Filozofski fakultet, Odsek za srpski jezik i lingvistiku. (štampano ćirilicom)

Milosavljević, B. (1994). Srpsko-francuski rečnik idioma i izreka. Beograd: Srpska književna zadruga. (štampano ćirilicom)

Otašević, Đ. (2012). Frazeološki rečnik srpskog jezika. Novi Sad: Prometej. (štampano ćirilicom)

Rey, A. (2000). Le Robert, Dictionnaire historique de la langue française. Paris: Dictionnaires Le Robert.

RSANU: Rečnik srpskohrvatskog književnog i narodnog jezika. (1959-2007). Beograd: SANU. (štampano ćirilicom) 
RSJ: Rečnik srpskoga jezika. (2007). Novi Sad: Matica srpska. (štampano ćirilicom) Seco, M., Andrés, O. \& Ramos, G. (2009). Diccionario fraseológico documentado del español actual: locuciones y modismos españoles. Madrid: Aguilar.

TLFi: Trésor de la langue française: dictionnaire de la langue du XIX et du XX siècle. (1971-1994). Paris: Éd. du CNRS - Klincksieck: Gallimard. 